\title{
Enhancing Power Quality in PV-SOFC Microgrids Using Improved Particle Swarm Optimization
}

\author{
V. P. Vinod \\ Dept. of Electrical and Electronics Engineering, Saveetha \\ College of Engineering, SIMATS, Chennai, India \\ mail2vinodvp@gmail.com.
}

\author{
N. Albert Singh \\ Bharat Sanchar Nigam Limited \\ Chennai, India \\ basisngc@gmail.com
}

\begin{abstract}
The concept of hybrid microgrid (MG) has attracted tremendous attention in modern electricity markets, owing to the enhanced efficiency and reliability it offers to the main electricity grid. Numerous meritorious aspects associated with hybrid MGs are the key features of future large scale renewable technologies. In this paper, a hybrid MG using PV-SOFC (PhotoVoltaic - Solid Oxide Fuel Cell) is connected to an infinite bus bar, in order to achieve an autonomous working mode. The dynamic and steadystate operation with control strategies for both PV and SOFC power systems are analyzed. The objective is to control the voltage and frequency of the MG when it is not connected to the main grid. Typically, an efficient control strategy must assess the power conversion system and its state, in the isolated MG. Moreover, it must reliably handle variant and intermittent type of loads. With this viewpoint, we propose a Voltage Source Inverter (VSI) based Proportional Integral (PI) controller, optimized by Improved Particle Swarm Optimization (IPSO) for the purpose of smooth power flow control improving power quality. The performance of PI-IPSO and PI technologies are evaluated, for the proposed MG, in MATLAB/Simulink. The results obtained verify the effectiveness of the modified PSO algorithm, in comparison to the conventional PI techniques, for the frequency and voltage control of the MG.
\end{abstract}

Keywords-Solid Oxide Fuel Cell (SOFC); Voltage Source Inverter (VSI); Proportional Integral Controller (PI); Microgrid (MG); Improved Particle Swarm Optimization (IPSO); Distributed Generators (DG)

\section{INTRODUCTION}

According to [1] 1.3 billion people are deprived of electricity. This predominantly happens due to the fact that a large part of population in developing countries lives in rural areas lacking access to the main utility grid. Therefore, rural electrification primarily relies on several other options for power generation to meet the needs, such as renewable sources or diesel power plants [1]. The prime advantage of such grids is that they can operate in both isolated and interconnected mode, with respect to the main grid. Generally, a microgrid (MG) comprises of several micro sources and interconnected energy storage systems. In isolated operation, a MG can be considered as a weak electrical grid that demands critical attention to frequency and voltage control in order to meet power demands and quality. Economic and quality operation of $\mathrm{MG}$ is a research challenge. Therefore, scheduling the output of distributed power and energy storage units in an MG becomes essential to the improvement of energy efficiency and the reduction of the power generation cost [2]. In this context, various economic operation models, at different constrained conditions for MG, are analyzed in [3]. In [4], optimal energy allocation considering various Distributed Generators (DG) is scrutinized. Identical analysis is performed in [5], where, the MG economic operation in isolated conditions is investigated. As concluded from the above works, optimizing the $\mathrm{MG}$ operation plays a key role to assure optimal power distribution and quality. Therefore, MG optimization becomes inevitable and such issues can be treated as a dynamic, multi-dimensional, nonlinear optimization problem $[6,7]$. For this purpose, many optimization techniques have been deployed, whose capabilities approach to meet the desired power quality, although their frequency and voltage magnitudes are questionable, and therefore need advancement.

This article demonstrates a new hybrid MG system which interfaces both PhotoVoltaic (PV) and Solid Oxide Fuel Cell (SOFC) as DG units. For optimal power flow, a conventional Proportional Integral (PI) controller is designed and implemented in Matlab. Improved Particle Swarm Optimization (IPSO) is utilized to tune the PI control parameters. Note that a similar technique, based on Genetic Algorithm (GA), is utilized for $\mathrm{MG}$ optimization in [8]. However, lack of randomness and the incapability to preserve good solutions were notable drawbacks. The proposed IPSO method, establishes an excellent tradeoff between exploration and exploitation processes, by incorporating an error index function that subsequently improves the solution. As a result, IPSO is reliable to attain good solutions. In this work, the developed IPSO algorithm is implemented in order to find the optimal power parameters, in order to achieve reliable voltage and frequency control for an actual-time salivating method of PI controller for both isolated and load change conditions. The main contributions of this paper are:

- A PV-SOFC, DC/AC MG is developed and implemented in order to reduce different switching transformations, so as to enhance the system efficiency.

- IPSO tuned PI controller with VSI is conceptualized, implemented and validated, in order to ensure the dynamic and stable operation by adjusting voltage and frequency. 
- Detailed power quality analysis is performed to validate the performance of the proposed control strategy.

\section{SYSTEM DESCRIPTION AND MODELING}

Figure 1 shows the overall structure of the grid-connected MG incorporating PV-SOFC considered in this work. Here a PV-SOFC MG is developed to validate the efficiency and effectiveness of the controllers. The MG comprises of PV arrays and an SOFC unit. They are connected to the utility grid through VSI and transformers. The VSI converts set DC supply into AC and supplies it to the $\mathrm{MG}$ at point of common coupling (PCC), thus voltage and frequency have to be maintained constant by the PI controller. The autonomous mode results in the disconnected operation of MG from the utility grid. DC-DC boost converters are used to amplify the profile of voltage and to obtain the maximum power from photovoltaic panels, which use the MPPT by implementing the Perturb and Observe (P\&O) algorithm [9, 10]. The MG configuration ensures that the controller designer must choose an appropriate strategy for making a trade-off between rapidity, accuracy and stability, for attaining good dynamic performance. Modeling of the system along with its control techniques are elaborated in detail in the coming sections.

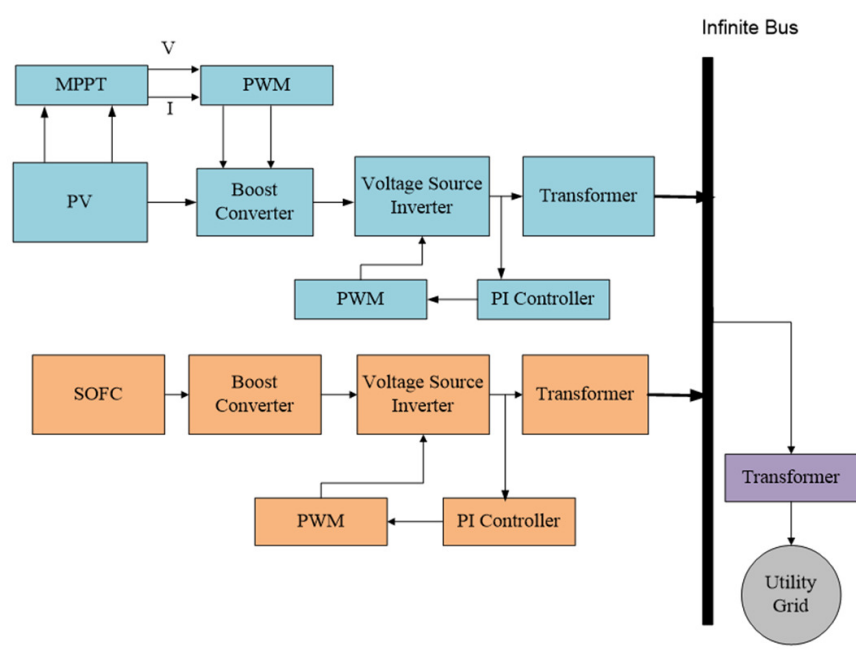

Fig. 1. PV SOFC MG structure

\section{A. PV Modeling}

PV systems are modeled from the single diode model concept, which has a source of current $I_{p h}$ and diode (D) connected avertedly. For accurate emulation in all operating conditions, series resistance $R_{s}$ and parallel resistance $R_{p}$ are also mathematically modeled. The typical current output equation from a single diode PV model is expressed as [11]:

$$
\begin{aligned}
I_{P V}= & N_{P} * I_{P h}-N_{P} * I_{O}\left[\exp \left(\frac{q * V_{P V}+I_{P V} R_{S}}{N_{S} K A T}\right)-1\right] \\
& -V_{P V}+\left(I_{P V} R_{S}\right) / R_{S h}
\end{aligned}
$$

where $I_{o}$ denotes the current in diode $(\mathrm{A}), I_{p v}$ denotes the PV output current (A), $N_{P}$ indicates the number of cells connected in parallel, $N_{S}$ represents the number of cells connected in series, $K$ is the Boltzmann coefficient, $q$ is the charge of an electron (C) and $V_{P V}$ denotes the output PV voltage (V). For simulation, a PV module having the specifications illustrated in Table I is utilized. Note that for brevity only a brief explanation regarding PV modeling is provided in this article. For detailed explanations regarding the single diode model, see $[12,13]$

TABLE I. ELECTRICAL CHARACTERICS OF PV MODULE

\begin{tabular}{|c|c|}
\hline Description & Rating \\
\hline Power at Maximum Power Point & $210 \mathrm{~W}$ \\
\hline Open circuit voltage $\left(V_{o c}\right)$ & $52.5 \mathrm{~V}$ \\
\hline Short circuit current $\left(I_{s c r}\right)$ & $5.75 \mathrm{~A}$ \\
\hline Number of series cells $\left(N_{S}\right)$ & 36 \\
\hline Number of parallel cells $\left(N_{p}\right)$ & 1 \\
\hline Voltage at MPP & $42 \mathrm{~V}$ \\
\hline Current at MPP & $5 \mathrm{~A}$ \\
\hline
\end{tabular}

\section{B. SOFC Modeling}

Inside the fuel cell, energy conversion take place from chemical to electrical by several electrochemical reactions, thus it can be stated as a static electrochemical device. Fuel cells use hydrogen and oxygen oxidants as fuel, in order to fulfill the energy conversion. The ultimate byproduct is water and heat, thus the fuel cell can be termed as green fuel. Comparing to other conventional sources, the fuel cell is more efficient as it does not have moving parts. The mostly used electrolyte for SOFC is Yttria Stabilized Zirconia (YSZ) because of its highly chemical, purely ionic conductivity and high thermal stability $[14,15]$. The SOFC modeling is designed on the following hypotheses: i) Invariant FC temperature, ii) FC gases are ideal, iii) FC is reformed by hydrogen and air, iv) Only one pressure is mentioned inside the electrodes, and v) SOFC is designed according to Nernst's equation. The voltage over the FC stack $\left(V_{f c}\right)$ is given by:

$$
V_{f C}=N_{o}\left(E_{o}+\frac{R T}{2 F} \ln \left(\frac{\mathrm{PH}_{2} \mathrm{PO}_{2}{ }^{0.5}}{\mathrm{PH}_{2} \mathrm{O}}\right)\right)-r I_{f c}
$$

where $E_{o}$ denotes standard reversible cell potential $(\mathrm{V}), N_{o}$ denotes the quantity of cells in stack, $r$ is the internal resistance $(\Omega)$, and $\mathrm{PO}_{2}, \mathrm{PH}_{2} \mathrm{O}$ and $\mathrm{PH}_{2}$ are the partial pressures of oxygen, water and hydrogen. For detailed understanding on SOFC operation, the dynamics of SOFC are studied in [16]. For the considered hybrid MG, an SOFC module having the specifications specified in Table II is modeled and implemented in Matlab.

TABLE II. ELECTRICAL CHARACTERISTICS OF THE SOFC MODULE

\begin{tabular}{|c|c|}
\hline Description & Rating \\
\hline Absolute temperature (K) & 1273 \\
\hline Initial Current (A) & 100 \\
\hline Number of cells in series & 450 \\
\hline Faraday's constant (C/kmol) & $96.487 \times 10^{6}$ \\
\hline Universal gas constant (J/kmol K) & 8314 \\
\hline Ideal standard potential (V) & 1.18 \\
\hline Output Voltage (V) & 330 \\
\hline Output current (A) & 20 \\
\hline
\end{tabular}

\section{PROPOSED PI CONTROLLER STRATEGY}

The control circuit plays a vital role for generating pulses in order to trigger the switches in the VSI in order to generate pure sinusoidal waves and high quality power transferring from 
the distribution generators to the consumer sections. The system responses of the MG can be improved by optimizing properly the controller gains. IPSO method can be approached for optimizing the proportional gain $\left(K_{p}\right)$ and integral gains $\left(K_{i}\right)$ of the PI controller. The reference values of current are taken from the outer current loop of the system $[17,18]$.

$$
\begin{aligned}
& i_{d}^{*}=\left(V_{r e f}-V\right)\left(K_{p}+\frac{K_{i}}{s}\right) \\
& i_{q}^{*}=\left(f_{r e f}-f\right)\left(K_{p}+\frac{K_{i}}{s}\right)
\end{aligned}
$$

By utilizing inverter current and feed forward voltage loop, the dynamic and steady state responses of the MG can be improved. Considering reference voltage as the output of the controller in a synchronously rotating $d_{q}$ frame, straggled by inverse Park and Clarke transformation, the resultant reference voltage signals of the controller can be yielded in ' $\alpha \beta$ ' axis. PWM technique triggers VSI thereby helping to maintain THD values within limits. Expressions can be given under synchronous dq frame as:

$$
\begin{gathered}
{\left[\begin{array}{l}
v_{d}^{*} \\
v_{q}^{*}
\end{array}\right]=\left[\begin{array}{cc}
-K_{P} & -\omega_{L S} \\
\omega_{L S} & -K_{P}
\end{array}\right]\left[\begin{array}{l}
i_{d} \\
i_{q}
\end{array}\right]+\left[\begin{array}{cc}
K_{P} & 0 \\
0 & K_{P}
\end{array}\right]\left[\begin{array}{l}
i_{d}^{*} \\
i_{q}^{*}
\end{array}\right]+\ldots} \\
+\left[\begin{array}{cc}
K_{i} & 0 \\
0 & K_{i}
\end{array}\right]\left[\begin{array}{l}
X_{d} \\
X_{q}
\end{array}\right]
\end{gathered}
$$

Converting (5) into 'abc' and ' $\alpha \beta$ ' frame by using inverse Park and Clarke transformations respectively, results in:

$$
\begin{aligned}
& {\left[\begin{array}{l}
V_{a} \\
V_{b} \\
V_{c}
\end{array}\right]=\left[\begin{array}{ccc}
\cos \theta & -\sin \theta & 1 \\
\cos \left(\theta-\frac{2 \pi}{3}\right) & -\sin \left(\theta-\frac{2 \pi}{3}\right) & 1 \\
\cos \left(\theta+\frac{2 \pi}{3}\right) & -\sin \left(\theta+\frac{2 \pi}{3}\right) & 1
\end{array}\right]} \\
& {\left[\begin{array}{l}
V_{\alpha} \\
V_{\beta} \\
V_{0}
\end{array}\right]=\frac{2}{3}\left[\begin{array}{l}
V_{a} \\
V_{b} \\
V_{c}
\end{array}\right]\left[\begin{array}{ccc}
1 & -1 / 2 & -1 / 2 \\
0 & \sqrt{3} / 2 & -\sqrt{3} / 2 \\
1 / 2 & 1 / 2 & 1 / 2
\end{array}\right]}
\end{aligned}
$$

The transfer function of the L-filter is presented as [19]:

$$
f_{1}=f \frac{1}{1+s T_{i}}
$$

where ' $f$ ' is the unfiltered constant and $f_{l}$ the filtered one.

Conventional PI controllers are limited as they are incapable of setting the gain to suitable fixed values and regulating the control objectives automatically. Hence the expected V-F values can be obtained by optimizing the PI controller with the IPSO method (see Figure 2).

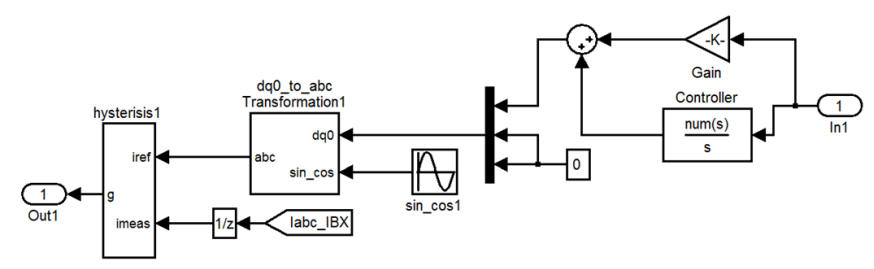

Fig. 2. Simulink diagram of the proposed PI controller

\section{A. Improved PSO for Voltage and Frequency Integrated Control}

PI controller gain tuning is based on the IPSO algorithm. This is an evolutionary optimization technique, modified from PSO, based on the swarming manners of bird gathering and fish scooping [20]. Each individual can be represented in two dimensions, based on their current position and velocity [21]. Particles accelerating towards their locations $P_{\text {best }}$ and $G_{\text {best }}$, with random weight and acceleration during iterations, are the elementary conceptions of the IPSO method. Here, IPSO is used for optimizing the PI controller gains, so (3) and (4) are modified to equalize the frequency and voltage of $\mathrm{MG}$ :

$$
\begin{aligned}
& f_{p u}=\left(\frac{f-0.5\left(f_{\max }+f_{\min }\right)}{0.5\left(f_{\max }+f_{\min }\right)}\right) \\
& V_{p u}=\left(\frac{V_{D C}-0.5\left(V_{\max }+V_{\min }\right)}{0.5\left(V_{\max }+V_{\min }\right)}\right)
\end{aligned}
$$

The 'max' represents the maximum limit of frequency and voltage whereas 'min' represents the minimum. The normalized values per unit are represented as pu. Calculated error values or fitness values can be obtained from the normalization of RHS of (9) and (10):

$$
E_{n}=f_{p u}-V_{p u}
$$

The error $E$ occurs between normalized voltage and frequency of the MG. This is achieved by:

$$
E\left(f_{i}^{k}, V_{i}^{k}\right)<E\left(f_{i}^{k-1}, V_{i}^{k-1}\right)
$$

where $E$ represents the generated error, $i$ represents particle number and $k$ represents the iteration process. Equation (12) calculates the normalized variance error, given to the PI controller.

In case of steady state, the error input to the controller will be zero. The PI controller output determines the amount of power to be transferred between the two sources through VSI. The flow chart of IPSO based on VSI-PI control is given in Figure 3.

\section{B. Fitness Function of IPSO}

Equation (13) gives the ITAE (integral time absolute error) as fitness function of the IPSO. The mathematical expression of the fitness function of the proposed IPSO technique can be written as:

$$
\text { ITAE }=\int_{0}^{t} t|e(t)| d t
$$

where $t$ is time and $e(t)$ is the difference between the reference set point and the measured signal (voltage/frequency). The maximum overshot of voltage and frequency at fixed gain values of PI controller have been given to IPSO algorithm to tune $k_{p}, k_{i}$, in order to minimize the error of maintaining the voltage and frequency level in the acceptable limit.

\section{SimUlation RESUlts AND DisCUSSION}

For selecting the optimal values of PI controller associated with the isolated MG systems, IPSO has been employed by minimizing the objective function. The obtained output results are compared with the PI and PI-IPSO based ones, to attain the same conditions of operation. Matlab/Simulink 2012a was used 
to model the three phase VSI connected to the grid, along with the controller. Matlab editor was used to implement the IPSO codes and minimize the selected objective function. The system includes an $88 \mathrm{~kW} \mathrm{PV}$, an $8 \mathrm{~kW}$ SOFC, while battery time constant is assumed as $5 \mathrm{~s}$.

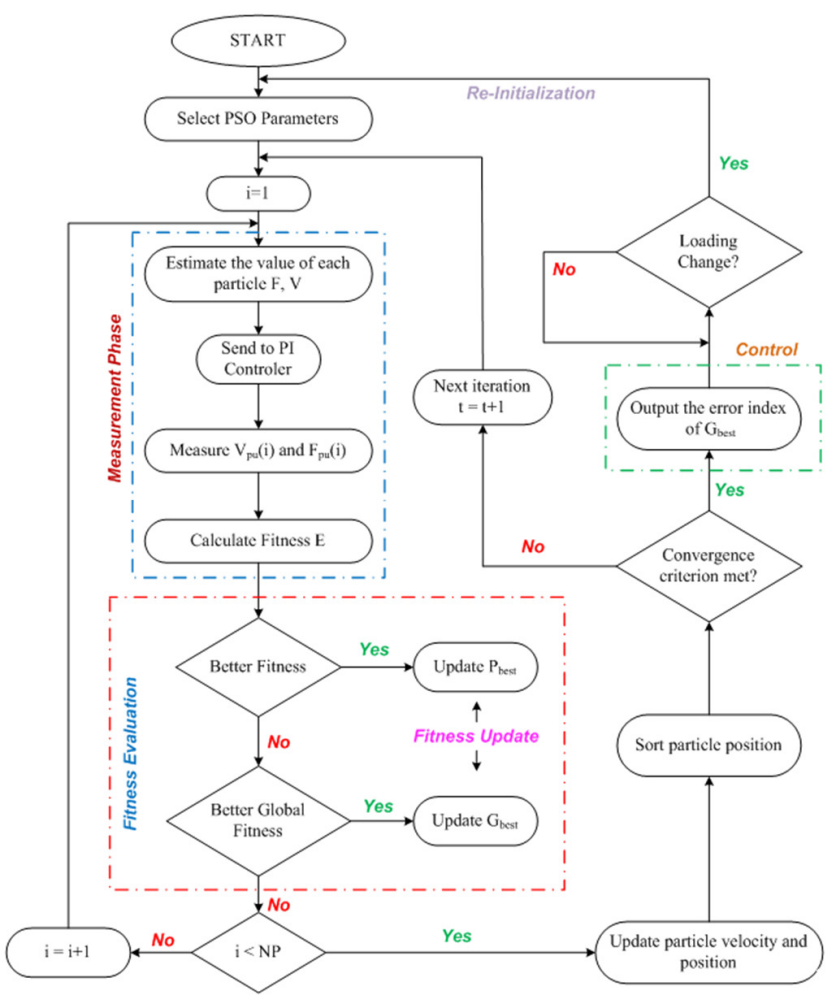

Fig. 3. Flow chart of IPSO based on VSI-PI control

\section{A. Regulation of Voltage and Frequency}

Optimal gain values can be attained by proper tuning of the PI controller by IPSO which leads to maintaining the MG parameters under its different operating conditions. V-F power control mode is adopted by the proposed algorithm in DG's, in order to compensate the addressed problems associated with voltage and frequency, due to the switching operations. When time is $0.5 \mathrm{~s}$, the MG switches to autonomous mode and a sudden drop in voltage occurs across the system components, like the load resistance and filter components. Immediately, VF control mode adopts IPSO optimized PI gain values as $K_{p}=1087$ and $K_{i}=3000$ for PV,$K_{p}=1045$ and $K_{i}=3000$ for SFOC. These optimal values reduce system's drops in voltages and frequency fluctuations, during different switching modes. The gain comparison of PI and PI-IPSO is given in Table III.

TABLE III. COMPARISON OF CONTROLLER GAINS

\begin{tabular}{|c|c|c|c|c|c|c|c|}
\hline \multicolumn{4}{|c|}{ PI Only } & \multicolumn{4}{c|}{ PI-IPSO } \\
\hline \multicolumn{2}{|c|}{ PV } & \multicolumn{2}{c|}{ SOFC } & \multicolumn{2}{c|}{ PV } & \multicolumn{2}{c|}{ SOFC } \\
\hline $\boldsymbol{K}_{\boldsymbol{p}}$ & $\boldsymbol{K}_{\boldsymbol{i}}$ & $\boldsymbol{K}_{p}$ & $\boldsymbol{K}_{\boldsymbol{i}}$ & $\boldsymbol{K}_{\boldsymbol{p}}$ & $\boldsymbol{K}_{\boldsymbol{i}}$ & $\boldsymbol{K}_{\boldsymbol{p}}$ & $\boldsymbol{K}_{\boldsymbol{i}}$ \\
\hline 1.059 & 3005.8 & 1.082 & 3012.2 & 1.078 & 3000 & 1.045 & 3000 \\
\hline
\end{tabular}

The MG model under study is switched to autonomous mode at $0.5 \mathrm{~s}$. The contrast is that, in this mode, the output waveforms with PI controller have more ripples than the model with PI tuned IPSO controller. Better dynamic response is offered by the PI-IPSO controller and the MG attains the nominal values for the voltage and frequency within a short settling time of $0.03 \mathrm{~s}$. Frequency regulation can be evaluated from Figures 4 and 5. While considering-model peak overshoot and settling time, stable operation is attained quickly in PI tuned IPSO and is within the boundary limits.

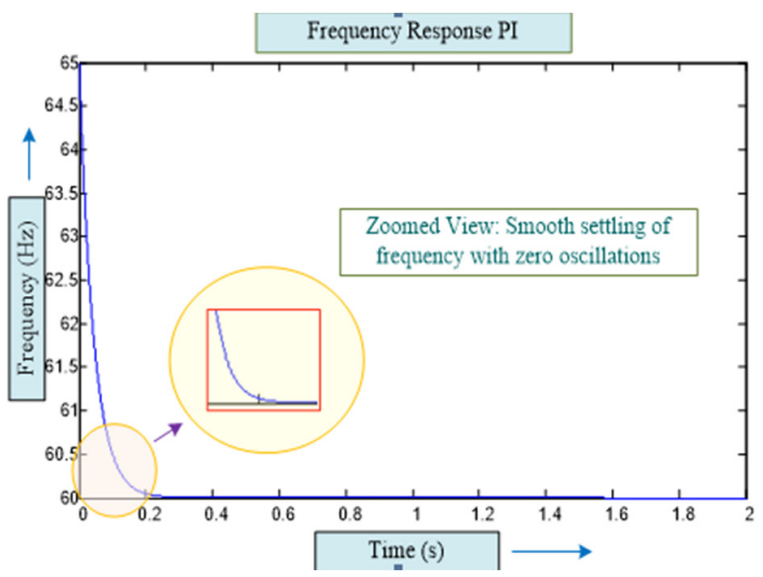

Fig. 4. Regulated MG frequency with PI Controller

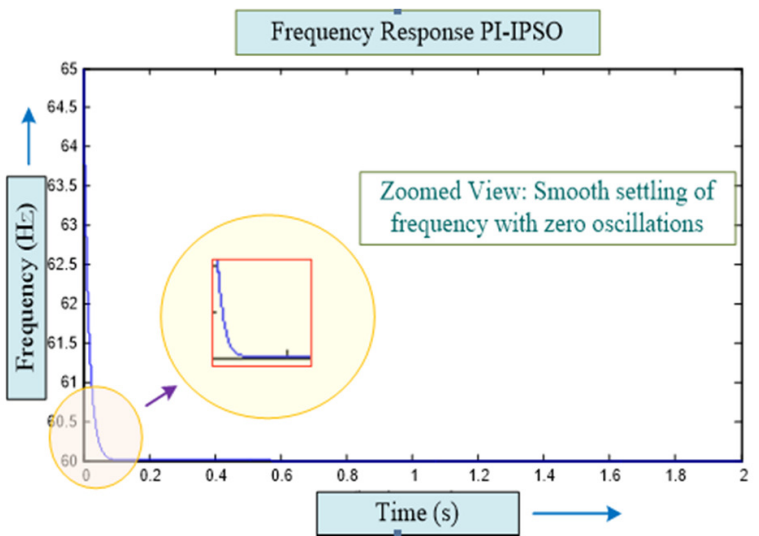

Fig. 5. Regulated frequency of MG with IPSO controller

\section{B. Response of the System.}

The main objective of this work is to take care of the quality of the MG outputs and maintain their sinusoidal nature, when the system operates in isolated mode. Figures 6 and 8, show the inverter's output. During isolated mode the MG control scheme has the sole responsibility to maintain the quality of power. MG output voltage and current waveforms at Point of Common Coupling (PCC), are shown in Figures 7 and 9, for the simple and tuned with IPSO PI controller respectively. The waveforms are significant and are sinusoidal. Fast Fourier Transform (FFT) analysis is carried out for finding the Total Harmonic Distortion (THD) in order to calculate the quality of power. 


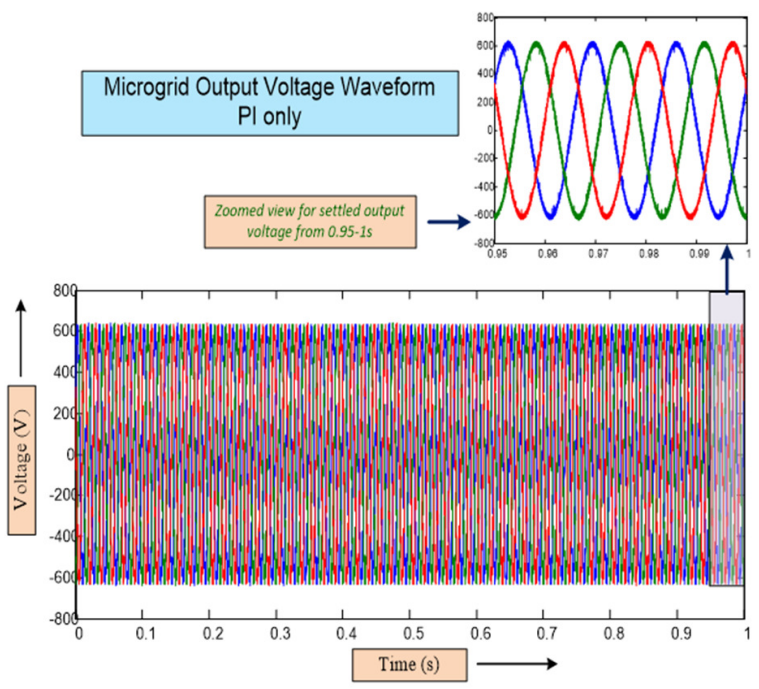

Fig. 6. Output voltage waveform of MG with PI

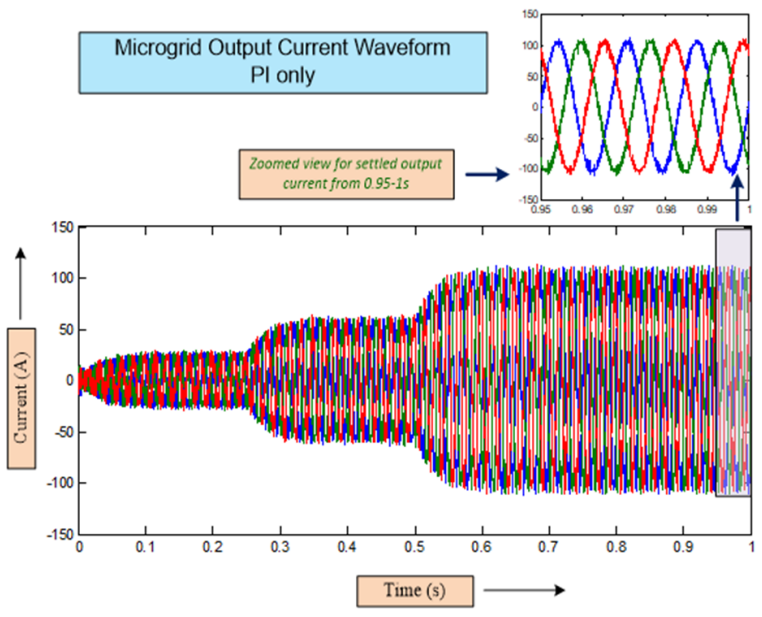

Fig. 7. Output current waveform of MG with PI

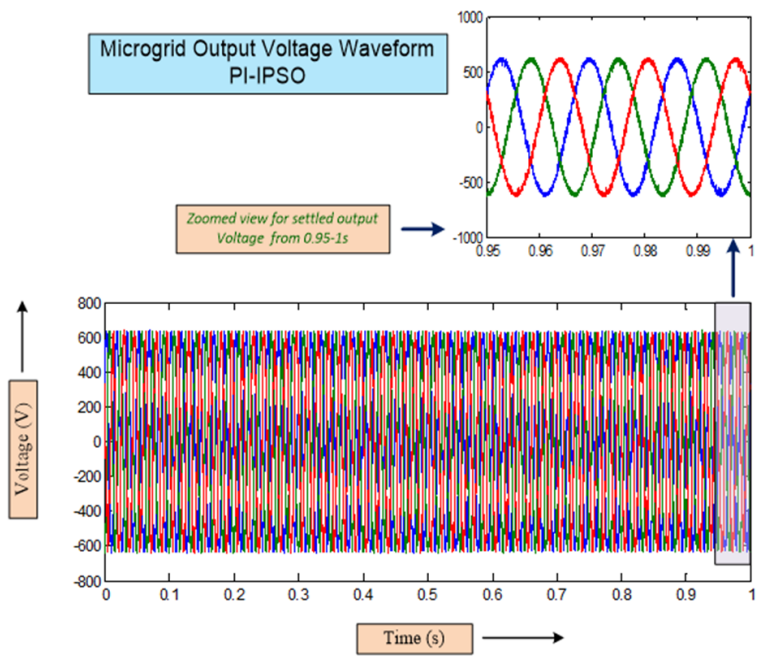

Fig. 8. Output voltage waveform of MG with IPSO-PI

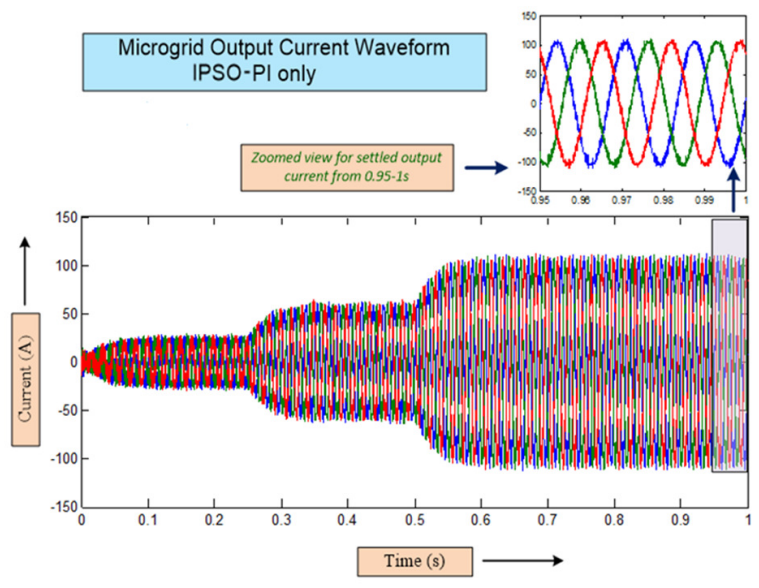

Fig. 9. Output current waveform of MG with IPSO-PI

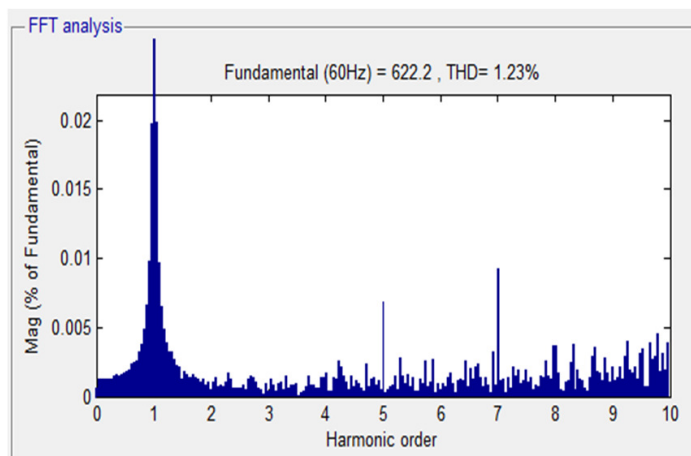

Fig. 10. THD spectrum of MG for inverter voltage with PI

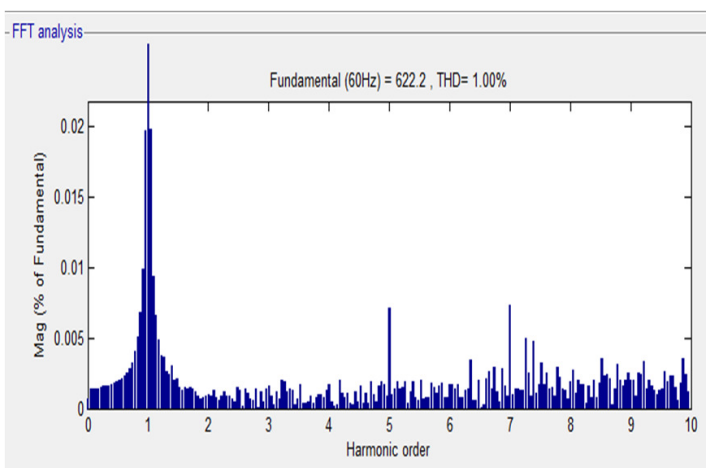

Fig. 11. THD spectrum of MG for inverter voltage with PI-IPSO

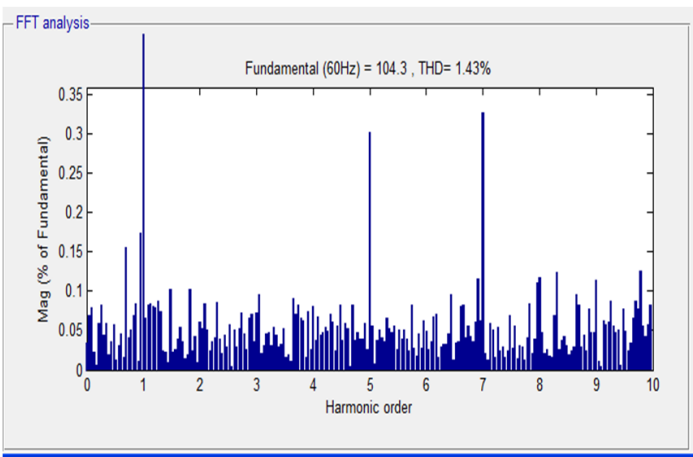

Fig. 12. THD spectrum of MG for phase current with PI 


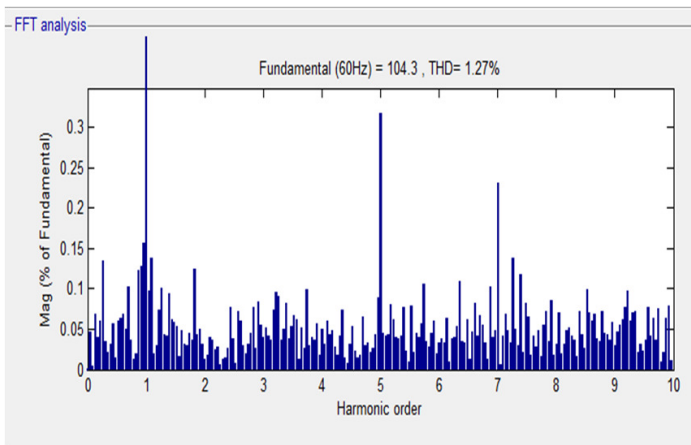

Fig. 13. THD spectrum of MG for phase current with PI-IPSO

THD analysis gives a clear picture of the quality of the power which is supplied by the MG. Pure sinusoidal nature of the output gives the accuracy of optimization of the PI controller parameters. FFT analysis is carried out and the results are shown in Figures 10 to 13, showing that the output from IPSO tuned PI controller has minimum THD values. Table IV gives a comparison of the odd harmonics up to 9th order for both PI and PI tuned IPSO. This analysis is carried out on phase Voltage and phase current of the MG. From Tables IV and V it is evident that the IPSO based controller has smaller THD values. The values obtained are $1.00 \%$ for output voltage and $1.27 \%$ for the output current. As per IEEE standard 1547-2003 [22], THD values of electric supply should be within the limit of 5\%. These results show the effectiveness of the IPSO tuned PI controller in maintaining the power quality of the system and in the regulation of voltage and frequency.

TABLE IV. THD ANALYSIS FOR PHASE VOLTAGE

\begin{tabular}{|c|c|c|c|c|c|c|}
\hline \multirow{4}{*}{ THD Level } & \multicolumn{6}{|c|}{ THD (\%) } \\
\hline & \multicolumn{6}{|c|}{ Phase Voltage } \\
\hline & \multicolumn{3}{|c|}{ PI (1.23\%) } & \multicolumn{3}{|c|}{ PI-IPSO (1.00\%) } \\
\hline & 1 & 2 & 3 & 1 & 2 & 3 \\
\hline 3rd & 0.01 & 0.01 & 0.01 & 0.01 & 0.01 & 0.01 \\
\hline 5th & 0.04 & 0.05 & 0.05 & 0.01 & 0.01 & 0.01 \\
\hline 7th & 0.06 & 0.05 & 0.06 & 0.01 & 0.01 & 0.01 \\
\hline 9th & 0.01 & 0.02 & 0.03 & 0.01 & 0.01 & 0.01 \\
\hline
\end{tabular}

TABLE V. THD ANALYSIS FOR PHASE CURRENT

\begin{tabular}{|c|c|c|c|c|c|c|}
\hline \multirow{3}{*}{ THD Level } & \multicolumn{6}{|c|}{ THD (\%) } \\
\cline { 2 - 7 } & \multicolumn{5}{|c|}{ PI (1.43\%) } & \multicolumn{2}{c|}{ PI-IPSO (1.27\%) } \\
\cline { 2 - 7 } & $\mathbf{1}$ & $\mathbf{2}$ & $\mathbf{3}$ & $\mathbf{1}$ & $\mathbf{2}$ & $\mathbf{3}$ \\
\hline 3rd & 0.07 & 0.05 & 0.12 & 0.04 & 0.03 & 0.03 \\
\hline 5th & 0.3 & 0.31 & 0.35 & 0.32 & 0.3 & 0.35 \\
\hline 7th & 0.33 & 0.28 & 0.3 & 0.23 & 0.22 & 0.27 \\
\hline 9th & 0.11 & 0.01 & 0.12 & 0.03 & 0.06 & 0.07 \\
\hline
\end{tabular}

\section{SUMMARY}

A PV-SOFC MG controlled by an IPSO tuned PI controller is projected in this work. Performance analysis of the parameters is conducted when the MG is set to operate in an autonomous mode. Regulation of Voltage and frequency in a VSI based DG unit using PI controller is discussed. The optimization of the controller helps setting the gain values, in order to attain minimized error. THD analysis of the proposed system with PI controller and IPSO tuned PI is evaluated.
Under the same operating conditions and controller configuration, PI-IPSO controller provides better steady and dynamic state response when compared to conventional PI controller, while delivering quality power to the grid. The suggestion of implementing the hardware is still under consideration.

\section{REFERENCES}

[1] R. H. Lasseter, "MicroGrids", 2002 IEEE Power Engineering Society Winter Meeting, New York, USA, January 27-31, 2002

[2] A. Y. Saber, G. K. Venayagamoorthy, "Plug-in vehicles and renewable energy sources for cost and emission reductions", IEEE Transactions on Industrial Electronics, Vol. 58, No. 4, pp. 1229-1238, 2011

[3] F. Katiraei, M. R. Iravani, P. Lehn, "Microgrid autonomous operation during and subsequent to islanding process", IEEE Power Engineering Society General Meeting, Denver, USA, June 6-10, 2004

[4] S. Mizani, A. Yazdani, "Optimal design and operation of a gridconnected microgrid", Electrical Power \& Energy Conference (EPEC), Montreal, Canada, October 22-23, 2009

[5] M. Fathi, H. Bevrani, "Adaptive energy consumption scheduling for connected microgrids under demand uncertainty",IEEE Transactions on Power Delivery, Vol. 28, No. 3, pp. 1576-1583, 2013

[6] Y. del Valle, G. K. Venayagamoorthy, S. Mohagheghi, J. Hernandez, R. G. Harley, "Particle swarm optimization: basic concepts, variants and applications in power systems", IEEE Transactions on Evolutionary Computation, Vol. 12, No. 2, pp.171-195, 2008

[7] L. D. Arya, L. S. Titare, D. P. Kothari, "Improved particle swarm optimization applied to reactive power reserve maximization", International Journal of Electrical Power \& Energy Systems, Vol. 32, No. 5, pp. 368-74, 2010

[8] R. Hassan, B. Cohanim, O. de Weck, G. Venter, "A comparison of particle swarm optimization and the genetic algorithm", 46th AIAA/ASME/ASCE/AHS/ASC Structures, Structural Dynamics and Materials Conference, Austin, USA, April 18-21, 2005

[9] S. Hota, M. K. Sahu, J. M. R. Malla, "A standalone PV system with a hybrid P\&O MPPT optimization technique”, Engineering, Technology \& Applied Science Research, Vol. 7, No. 6, pp. 2109-2112, 2017

[10] S. Latreche, A. E. Badoud, M. Khemliche, "Implementation of MPPT algorithm and supervision of shading on photovoltaic module", Engineering, Technology \& Applied Science Research, Vol. 8, No. 6, pp. 3541-3544, 2018

[11] R. Abbassi, A. Boudjemline, A. Abbassi, A. Torchani, H. Gasmi, T. Guesmi, "A numerical-analytical hybrid approach for the identification of SDM solar cell unknown parameters", Engineering Technology \& Applied Science Research, Vol. 8, No. 3, pp. 2907-2913, 2018

[12] J. P. Ram, H. Manghani, D. S. Pillai, T. S. Babu, M. Miyatake, N. Rajasekar, "Analysis on solar PV emulators: A review", Renewable and Sustainable Energy Reviews, Vol. 81, No. 1, pp. 149-60, 2018

[13] D. S. Pillai, B. Sahoo, J. P. Ram, A. Laudani, N. Rajasekar, N. Sudhakar, "Modelling of organic photovoltaic cells based on an improved reverse double diode model”, Energy Procedia, Vol. 117, pp. 1054-1061, 2017

[14] R. M. Ormerod, "Solid oxide fuel cells", Chemical Society Reviews, Vol. 32, No. 1, pp. 17-28, 2003

[15] J. Will, A. Mitterdorfer, C. Kleinlogel, D. Perednis, L. J. Gauckler, "Fabrication of thin electrolytes for second-generation solid oxide fuel cells", Solid State Ionics, Vol. 131, No. 1, pp. 79-96, 2000

[16] T. Vigneysh, N. Kumarappan, "Autonomous operation and control of photovoltaic/solid oxide fuel cell/battery energy storage based microgrid using fuzzy logic controller", International Journal of Hydrogen Energy, Vol. 41, No. 3, pp. 1877-91, 2016

[17] S. H. Qazi, M. W. Mustafa, N. Hussain, U. Sultana, "Performance evaluation of PI and PI-PSO in improving power quality of an autonomous microgrid", IET International Conference on Resilience of Transmission and Distribition Networks, Birmingham, UK, September 26-28, 2017 
[18] S. Mikkili, A. K. Panda, "SHAF for mitigation of current harmonics using pq method with PI and fuzzy controllers", Engineering, Technology \& Applied Science Research, Vol. 1, No. 4, pp. 98-104, 2011

[19] B. H. Kwon, B. D. Min, J. H. Youm, “An improved space-vector-based hysteresis current controller", IEEE Transactions on Industrial Electronics, Vol. 45, No. 5, pp. 752-760, 1998

[20] X. Wu, Z. Piao, Y. Liu, H. Luo, "Reactive power and voltage control based on improved particle swarm optimization in power system", 8th World Congress on Intelligent Control and Automation, Jinan, China, July 7-9, 2010

[21] N. H. Saad, A. A. El-Sattar, A. E. Mansour, "A novel control strategy for grid connected hybrid renewable energy systems using improved particle swarm optimization", Ain Shams Engineering Journal, Vol. 9, No. 4, pp. 2195-214, 2018

[22] S. H. Qazi, M. W. Mustafa, U. Sultana, N. H. Mirjat, "Current harmonics mitigation from grid connected variable speed wind turbine due to nonlinear loads using shunt active power filter", Jurnal Teknologi, Vol. 79, No. 4, pp. 45-53, 2017 